\title{
Strategi Penggunaan Aplikasi Android dalam Meningkatkan Sistem Informasi Wisata Gastronomi Kota Ternate
}

\author{
Heni Pridia Rukmini Sari ${ }^{1}$, Lioe Lyly Soemarni ${ }^{2}$ dan Dewi Turgarini ${ }^{3}$ \\ ${ }^{1}$ Program Studi Hospitaliti \& Pariwisata Institut Stiami, Indonesia \\ ${ }^{2}$ Program Studi Usaha Perjalanan Wisata, Politeknik Sahid, Indonesia \\ ${ }^{3}$ Program Studi Manajemen Industri Katering, FPIPS, UPI, Indonesia \\ Email korespondensi: heni.pridia@gmail.com
}

\begin{abstract}
ABSTRAK
Kota Ternate di Provinsi Maluku Utara memiliki keanekaragaman warisan budaya sebagai penopang wisata gastronomi yang tetap melestarikan budaya lokal, sebagai produk wisata asli yang unik, dan otentik. Daya tarik wisata ini menjadi salah satu pilihan bagi para wisatawan lokal, nusantara dan mancanegara untuk mendapatkan pengalaman saat melakukan kegiatan wisata mencicipi aneka menu sebagai hidangan asli Ternate di restoran sebagai specialities restaurant, membeli aneka suvenir oleh-oleh khas Ternate, melihat atraksi pembuatan makanan dan minuman Ternate lengkap dengan story telling sebagai identitas etnik penduduk asli Kota Ternate. Lokasi tujuan wisata gastronomi yang banyak mengakibatkan pengunjung sulit mencari lokasi dan restoran yang sarat makna dan sesuai dengan yang diinginkan apalagi dengan rute perjalanan di Kota Ternate yang memiliki beberapa titik yang hanya satu arah. Adanya perkembangan teknologi mobile berbasis linux seperti android sebagai sistem operasi smartphone yang cukup populer di kalangan masyarakat umum. Android memiliki biaya yang tergolong murah dan bersifat opensource memungkinkan pengguna dapat mengembangkan fitur pemetaan yang komprehensif dengan komponen atraksi wisata gastronomi di Kota Ternate seperti restoran, pusat oleh-oleh, tempat penyelenggaraan cooking class, dan lainnya. Metode yang dilakukan dalam penelitian ini adalah penelitian eksploratif serta deskriptif analisis untuk mengumpulkan data yang memiliki komponen sebagai atraksi wisata yaitu nama restoran/pusat oleh-oleh/cooking class, lokasi, aksesibilitas, amenitas, pengelola, deskripsi, nilai unik dan unggul. Tujuan dari penelitian ini adalah untuk membuat desain android aplikatif tentang sistem informasi pemetaan wisata gastronomi yang komprehensif di Kota Ternate sebagai atraksi wisata yang dapat diakses secara online.
\end{abstract}

Kata Kunci: Wisata Gastronomi, Ternate, Sistem Informasi, Aplikasi Android

\begin{abstract}
The city of Ternate in North Maluku Province has a diversity of cultural heritage as a support for gastronomic tourism that still preserves local culture, as a unique, and authentic original tourist product. This tourist attraction becomes one of the options for local, archipelago and foreign tourists to get experience when doing tourist activities to taste various menus as authentic Ternate dishes in restaurants as specialities restaurants, buy souvenirs typical of Ternate, see ternate food and beverage making attractions complete with story telling as the ethnic identity of the indigenous people of Ternate City. The location of more and more gastronomic tourist destinations makes it difficult for visitors to find locations and restaurants that are full of meaning and in accordance with what is desired especially with travel routes in the city of Ternate that have several points that are only one way. The development of linuxbased mobile technology such as android as a smartphone operating system is quite popular among the general public. Android has a relatively low cost and opensource allows users to
\end{abstract}


develop comprehensive mapping features with components of gastronomic tourist attractions in the city of Ternate such as restaurants, souvenir centers, cooking class venues, and others. The methods carried out in this study are exploratory research and descriptive analysis to collect data that has components as tourist attractions, namely the name of the restaurant/souvenir center/cooking class, location, accessibility, amenities, managers, descriptions, unique and superior values. The purpose of this research is to create an applicative android design about a comprehensive gastronomic tourist mapping information system in Ternate City as a tourist attraction that can be accessed online.

Keywords: Gastronomic Tourism, Ternate, Information Systems, Android Apps

\section{PENDAHULUAN}

UNESCO telah menetapkan kriteria kota gastronomi dan sudah terdapat beberapa kota di dunia yang diakui sebagai kota gastronomi, seperti Alba (Italia), Gaziantep (Turki), Östersund (Swedia), Chengdu (Tiongkok), Jeoniu (Korea Selatan), Rasht (Iran), serta Tsuruoka (Jepang). Kota-kota ini memiliki beragam aktivitas atraksi wisata gastronomi, yaitu kuliner, bahan baku, cara mencicipi, cara menghidangkan, sarana edukasi, pengalaman yang unik, kandungan nutrisi dan gizi, sejarah/tradisi/filosofi hingga etika dan etiketnya (Turgarini, 2018).

Kota Ternate adalah salah satu kota yang memiliki keragaman corak dan budaya, termasuk keanekaragaman gastronomi, seperti rumah makan dengan menu khasnya, wilayah tempat tumbuhnya bahan baku otentik, tempat untuk mencicip dan menghidangkan sajian yang sarat nilai kearifan lokal, lembaga pendidikan gastronomi, adanya pengalaman yang berkesan saat berkunjung ke destinasi wisata, adanya manfaat bagi kesehatan saat menikmati makanan/minuman karena adanya kandungan gizi yang jelas, serta adanya sejarah/tradisi/filosofi dan etika dan etiket saat menikmati kuliner khas tersebut. Keanekaragaman gastronomi di Kota Ternate ini dapat dikembangkan oleh seluruh stakeholder sebagai bagian dari wisata gastronomi.

Lokasi destinasi wisata gastronomi tersebut tersebar di seluruh penjuru kota sehingga mengakibatkan penikmat gastronomi tidak dengan mudah menemukan lokasi destinasi wisata gastronomi sesuai dengan yang diinginkan. Selama ini mereka menggunakan cara manual untuk mencari lokasi tujuan wisata gastronomi dan ternyata kurang efektif karena menghabiskan banyak waktu.

Di sisi lain perkembangan teknologi mengarah kepada teknologi mobile seperti Android yang merupakan sistem operasi smartphone yang cukup populer di masyarakat. Android adalah sistem operasi perangkat mobile berbasis Linux. Salah satu kelebihan Android dibandingkan dengan sistem operasi perangkat lainnya adalah Android tergolong murah dibandingkan dengan sistem operasi smartphone lainnya. Selain itu Android bersifat opensource sehingga pengguna dapat mengembangkat fitur yang belum ada sesuai keinginan mereka.

Belum adanya aplikasi sistem informasi yang komprehensif mengenai destinasi wisata gastronomi di Kota Ternate membuat penulis berusaha untuk merancang sebuah aplikasi yang mampu menampilkan dan menyajikan informasi tentang gastronomi khas Ternate yang sarat identitas kearifan lokal (bahan baku, menu, restoran, home industry, cooking class, pusat oleholeh, story telling). Aplikasi tersebut juga dilengkapi dengan informasi mengenai jarak tempuh terpendek menuju destinasi wisata gastronomi yang dapat diakses menggunakan aplikasi sistem informasi Android tersebut.

Oleh karena itu maka rumusan masalah dalam penelitian ini adalah:

1) Bagaimana mengembangkan suatu sistem pencarian lokasi tujuan wisata gastronomi Ternate sebagai atraksi wisata gastronomi di Kota Ternate berbasis aplikasi Android? 
2) Bagaimana menyajikan informasi yang edukatif dan komprehensif tentang atraksi wisata gastronomi di Kota Ternate berbasis aplikasi Android?

\section{TINJAUAN PUSTAKA}

\section{Gastronomi, Foodscape dan Pariwisata}

Gastronomi dan pariwisata memiliki hubungan yang berkembang pesat dalam beberapa dekade terakhir (Richards, 2015). Hubungan antara gastronomi dan pariwisata bergeser dari sekadar "perangkat tujuan" menjadi "alasan utama" wisatawan untuk mengunjungi destinasi. Penyebab pergeseran tersebut adalah karena perubahan posisi sosial gastronomi dan ekonomi. Di samping itu, gastronomi membuat hubungan antara foodscape, identitas, budaya dan pariwisata menjadi penting dan signifikan di dalam 'network society' (Castells, 2009).

Richards (2015) juga menyatakan bahwa pada awalnya gastronomi lebih sering dipandang sebagai kebutuhan dibandingkan daya tarik wisata, dengan penekanan pada pelayanan terhadap tamu secara efisien dan semurah mungkin. Yang berperan di sini adalah produsen. Gastronomi lalu berkembang dengan adanya kerjasama antara produsen dan konsumen dimana produsen memberikan ruang kepada konsumen untuk menunjukkan keterampilannya. Kini, gastronomi berkembang menyesuaikan perilaku konsumen dengan mempertukarkan pengalaman, pengetahuan dan keterampilan (atau keinginan untuk belajar keterampilan) antara masyarakat lokal dan pelancong (Richards, 2015). Sebagai contoh, wisatawan yang berkunjung ke Pasar Boqueria di Barcelona dapat membeli makanan lokal di tempat itu dan kemudian belajar memasak hidangan lokal dengan menggunakan bahan-bahan yang tersedia (Ilincic 2014). Pada tahap ini seperti dikatakan oleh Williams et al. (2014) masyarakat mengetahui bahwa pariwisata gastronomi bisa menjadi ceruk pasar yang berdampak meningkatnya pendapatan. Makanan adalah motivasi wisatawan untuk rekreasi, sedangkan foodscape, khususnya lokasi atau destinasi, berfungsi sebagai wahana untuk mencari pengalaman gastronomi.

Lebih lanjut, Richards (2015) mengatakan bahwa gastronomi sangat berguna untuk aktivitas pariwisata karena merupakan pintu gerbang masuk ke budaya lokal yang dapat membuat wisatawan dan penduduk lokal menikmati pengalaman budaya bersama. Gastronomi adalah bagian sentral dari pengalaman wisata yang akan memberikan pengalaman berkesan dan bermakna bagi wisatawan. Selain itu, gastronomi dapat menjadi elemen khas dari brand image tempat (Richards, 2012), khususnya destinasi wisata, sehingga dapat menjadi sumber identitas, bahkan menciptakan identitas baru yang sifatnya hybrid (Scarpato, 2002).

Dalam konteks ini, gastronomi tidak lepas dari hasil cipta, rasa, karsa, dan karya masyarakat. Sebagai pusaka budaya, gastronomi dapat berhubungan simbiosis mutualisme dengan pariwisata. Hjalager dan Richards (2002) mengatakan bahwa gastronomi lokal dapat memainkan peran yang berbeda dalam pariwisata, misalnya sebagai produk pelengkap destinasi wisata, dan sebagai gourmet pariwisata (Hall et al., 2003), atau dapat dipandang pula sebagai lambang atau simbol kekhasan lokal (Bonow \& Rytkönen, 2012). Kala wisatawan memilih gastronomi lokal maka mereka juga merasakan unsur karakter lokal daerah yang dikunjunginya (Bessière, 1998).

Jadi, dengan mengonsumsi gastronomi di Kota Ternate artinya menyerap dan mewujudkan serta menikmati secara intrinsik wisata dengan aura lokalitas yang bahkan legendaris. Biasanya di daerah wisata banyak gastronomi lokal yang ditangani oleh artisan setempat sehingga dipandang sebagai bagian penting dari warisan dan budaya lokal. Tellström et al (2005) menyatakan gastronomi lokal merupakan keunggulan kompetitif dan daya tarik untuk bisnis wisata. Namun demikian, Yi-Chin et al (2011) berpendapat bahwa di dalam pariwisata gastronomi, sebaiknya nilai produk lokal diperluas sehingga mampu meningkatkan kualitas pengalaman wisatawan dan menambah keunikan lokal. 
Long (2010) mengemukakan bahwa penciptaan gastronomi lokal yang khas dan pertumbuhan 'foodscapes' telah terjadi di banyak daerah di dunia. Dia juga menunjukkan interaksi antara kekuatan-kekuatan global dan lokal di tempat tersebut seringkali membentuk identitas gastronomi yang baru. Dengan begitu, kecenderungan yang terjadi pada saat ini bukan hanya menekankan pada pangan tertentu atau keahlian memasak yang tinggi, tapi justru pada sistem gastronomi secara keseluruhan, yaitu 'foodscape' atau budaya pangan. Hal ini selain disebabkan oleh persaingan global yang menjadi driving force satu destinasi agar memiliki perbedaan dengan destinasi yang lain, dalam upaya untuk menarik wisatawan, juga karena adanya gerakan masyarakat dari bawah ke atas (bottom-up) untuk mendorong munculnya identitas gastronomi lokal yang lebih besar dengan mengembangkan banyak foodscape (Richards, 2015).

Konteks pangan sebuah kota dapat menjadi magnit pariwisata, layaknya Candi Borobudur di Jawa Tengah dengan gaya sentripetal dan sentrifugalnya yang harus bergerak secara sinergis, dinamis dan harmonis. Gaya sentripetal merupakan kekuatan yang menarik dari luar ke dalam, sedangkan sentrifugal merupakan gaya melenting dari dalam ke luar (Baiquni, 2009). Sebuah kota memiliki regional branding lewat keunikan perpaduan antara cita rasa gastronomi dengan penyajian yang bernuansa alam sebagai daya tarik pengunjung untuk mendatanginya. Regional branding pada dasarnya digunakan sebagai alat pemersatu suatu wilayah dengan tujuan mendorong pertumbuhan ekonomi, pembangunan citra, pengenalan potensi daerah khususnya pariwisata (Wardani \& Baiquni, 2012).

Sementara itu, kekuatan sentrifugal merupakan gaya pendorong kota untuk selalu melakukan pengembangan melalui inovasi dan mempertajam kreativitas (Turgarini, 2018). Tujuannya adalah untuk menghindari stagnansi dan kejenuhan pariwisata yang dapat berakibat pada penurunan laju ketertarikan orang untuk mengunjunginya.

Cohen dan Avieli (2004) mengatakan wisata gastronomi akan membuat wisatawan terlibat lebih dalam dan mendapatkan pengalaman yang lebih banyak dengan lingkungan destinasi (dalam hal ini kota) yang dikunjunginya. Gastronomi merupakan bagian dari warisan sosial dan budaya masyarakat, dan hal itu mencerminkan gaya hidup orang yang tinggal di wilayah geografis yang berbeda dengan wisatawan serta memiliki keahlian memasak yang berakar pada budaya dan tradisi mereka sendiri (Mitchell \& Hall, 2006). Oleh sebab itu diperlukan upaya secara komprehensif dan multidisiplin untuk melakukan pariwisata gastronomi (gastronomic tourism) sebagai bagian dari kehidupan kota. Khususnya yang mengacu pada perjalanan (dalam konteks wisata gastronomi), yang dirancang dengan tujuan utama menjadikan gastronomi lokal sebagai faktor motivasi utama seseorang untuk melakukan perjalanan tersebut.

UNESCO (2015) menyatakan bahwa kota gastronomi perlu memenuhi kriteria sebagai berikut:

1. Berkembangnya keahlian memasak yang baik sehingga merupakan karakteristik dari pusat kota dan/atau wilayah;

2. Adanya komunitas yang memiliki keahlian memasak, dan terdapat banyak restoran dan/atau koki tradisional;

3. Penggunaan bahan baku lokal yang digunakan dalam memasak masakan tradisional; disertai pengetahuan lokal, praktik kuliner tradisional, dan metode memasak yang telah bertahan menghadapi industri atau kemajuan teknologi; tersedianya pasar makanan tradisional dan industri makanan tradisional;

4. Ada tradisi hosting festival gastronomi, adanya penghargaan, kontes dan sarana yang luas dan memiliki target lain yaitu mendapatkan pengakuan secara nasional dan internasional.

5. Ada penghormatan terhadap lingkungan dan promosi produk lokal yang berkelanjutan; 
6. Memiliki kemampuan mengelola suara rakyat, ada promosi gizi ke lembaga-lembaga pendidikan dan dimasukkannya program konservasi keanekaragaman hayati dalam kurikulum sekolah memasak.

Pengembangan pariwisata gastronomi dianggap merupakan strategi jitu pembangunan wisata perkotaan (urban tourism). Bartella (2011) menengarai gastronomi selama ini telah meningkatkan pemasukan daerah dari sektor pariwisata. Pariwisata gastronomi sifatnya padat karya dan dapat menciptakan lapangan kerja, memberikan kontribusi pada ekonomi regional sehingga memperkuat aspek perekonomian, mempertahankan warisan budaya dan lingkungan lokal, memperkuat identitas dan rasa memiliki masyarakat setempat, memperpanjang masa tinggal wisatawan atau musim pariwisata, umumnya tidak memerlukan investasi baru yang besar, menjadi jembatan dengan masa lalu, merangsang pertanian dan produksi pangan lokal, dan mengurangi kebocoran ekonomi. Di sini tampak bahwa pengembangan wisata bukan hanya fokus pada ekonomi, tapi juga sektor sosial dan budaya.

Sama halnya dengan Kota Ternate yang memiliki banyak tempat untuk menikmati gastronomi, baik yang dijajakan di kedai tradisional, kaki lima, restoran, maupun mal. Spektrum jenis makanan dan minuman, cara pengolahan bahan baku, cara mengantarkan kepada konsumen dan perilaku konsumennya, relatif luas. Unsur gastronomi lain yang ditampilkan di beberapa gerai adalah cara penyajiannya yang memiliki kekhasan etnis Ternate.

\section{Sistem Informasi}

Sistem informasi diartikan sebagai kombinasi dari teknologi informasi dan aktivitas orang yang menggunakan teknologi untuk mendukung operasi dan manajemen. Sedangkan dalam arti luas, sistem informasi adalah seperangkat komponen yang saling berhubungan yang berfungsi untuk mengumpulkan, memproses, menyimpan, dan mendistribusikan informasi untuk mendukung pembuatan keputusan dan pengawasan dalam organisasi (Husein dan Wibowo, 2006). Sistem informasi terdiri dari informasi tentang orang, tempat, dan sesuatu dalam organisasi atau lingkungan yang melingkupinya.

Sistem memiliki beberapa karakteristik atau sifat yang terdiri atas komponen sistem, batasan sistem, lingkungan luar sistem, penghubung sistem, masukan sistem, keluaran sistem, pengolahan sistem, dan sasaran sistem. Sedangkan pengertian informsi adalah data yang diolah menjadi lebih berguna dan berarti bagi penerimanya dan untuk mengurangi ketidakpastian dalam proses pengambilan keputusan mengenai suatu keadaan. Pengertian Sistem Informasi (SI) secara komprehensif, terdapat dalam uraian Jhon F. Nash yang menyatakan SI adalah kombinasi dari manusia, fasilitas atau alat teknologi, media, prosedur dan pengendalian yang bermaksud menata jaringan komunikasi yang penting, proses atau transaksi tertentu dan rutin, membantu manajemen dan pemakai intern dan ekstern dan menyediakan dasar pengambilan keputusan yang tepat. Hal ini sesuai dengan paparan Robert A. Leitch, Henry Lucas, dan Alter bahwa sistem informasi adalah suatau sistem dalam suatu organisai yang mempertemukan kebutuhan pengolahan transaksi harian, mendukung operasi, bersifat manajerial dan kegiatan strategi dari suatu organisasi dan menyediakan pihak luar tertentu (pelanggan) untuk mengambil keputusan dan pengendalian dengan informasi/laporan-laporan/ sumber daya yang diperlukan. Fungsi sistem informasi adalah:

1) Untuk meningkatkan aksesbilitas data yang ada secara efektif dan efisien kepada pengguna, tanpa dengan perantara sistem informasi.

2) Memperbaiki produktivtas aplikasi pengembangan dan pemeliharaan sistem.

3) Menjamin tersedianya kualitas dan keterampilan dalam memanfaatkan sistem informasi secara kritis.

4) Mengidentifikasi kebutuhan mengenai keterampilan pendukung sistem informasi.

5) Mengantisipasi dan memahami akan konsekuensi ekonomi.

6) Menetapkan investasi yang akan diarahkan pada sistem informasi. 
7) Mengembangkan proses perencanaan yang efektif.

\section{Pemetaan}

Menurut Soekidjo (1994), Juhadi, dan Liesnoor (2001), pemetaan adalah pengelompokan suatu kumpulan wilayah yang berkaitan dengan beberapa letak geografis wilayah yang meliputi dataran tinggi, pegunungan, sumber daya dan potensi penduduk yang berpengaruh terhadap sosial kultural yang memiliki ciri khas khusus dalam penggunaan skala yang tepat. Teknisnya adalah dalam pembuatan data, dilanjutkan dalam pengolahan data, dan penyajian dalam bentuk peta.

Permanasari (2007) mengemukakan terdapat tiga tahap proses pemetaan yang harus dilakukan, yaitu:

1. Tahap Pengumpulan Data adalah langkah awal dalam proses pemetaan. Data yang ditetapkan dapat berupa data primer atau data sekunder. Data yang dapat dipetakan adalah data yang bersifat spesial, artinya data tersbut terdistribusi atau terbesar secara keruangan suatu wilayah tertentu.

2. Tahap Penyajian Data adalah upaya melukiskan atau menggambarkan data dalam bentuk simbol, supaya data tersebut menarik, mudah dibaca dan dimengerti oleh pengguna (users). Penyajian data pada sebuah peta harus dirancang secara baik dan benar supaya tujuan pemetaan dapat tercapai.

3. Tahap Penggunaan Peta adalah merupakan tahap penting karena menentukan keberhasilan pembuatan suatu peta. Peta yang dirancang dengan baik akan dapat digunakan/dibaca dengan mudah. Peta merupakan alat untuk melakukan komunikasi, sehingga pada peta harus terjalin interaksi antar pembuat peta (map maker) dengan pengguna peta (map users). Pembuat peta harus dapat merancang peta sedemikian rupa sehingga peta mudah dibaca, diinterpretasi dan dianalisis oleh pengguna peta. Pengguna harus dapat membaca peta dan memperoleh gambaran informasi sebenarnya di lapangan (real world).

Hasil akhir dari pemetaan adalah peta sebagai representasi atau gambaran unsur-unsur atau kenampakan abstrak yang dipilih dari permukaan bumi atau benda-benda angkasa dan umumnya digambarkan pada satu bidang datar dan diperkecil atau diskalakan (ICA,1973 dalam Permanasari).

\section{Android}

Android adalah sistem operasi berbasis Linux yang dirancang untuk perangkat seluler layar sentuh seperti telepon pintar dan komputer tablet. Sistem operasi dilakukan dengan sumber terbuka (open source), dan google merilis kodenya dibawah lisensi Apache. Kode dengan sumber terbuka dan lisensi perizinan pada Android memungkinkan perangkat lunak untuk dimodifikasi secara bebas dan didistribusikan oleh pembuat perangkat, operator nirkabel dan pengembang aplikasi.

Android juga menjadi pilihan bagi perusahaan teknologi yang menginginkan sistem operasi berbiaya rendah, bisa dikustomisasi, dan ringan untuk perangkat teknologi tinggi. Android juga dikembangkan menjadi aplikasi tambahan di televisi, konsol permainan, kamera digital, dan perangkat elektronik lainnya. Sifat Android yang terbuka telah mendorong munculnya sejumlah besar komunitas pengembang aplikasi untuk menggunakan kode sumber terbuka sebagai dasar proyek pembuatan aplikasi, dengan menambahkan fitur-fitur baru bagi pengguna tingkat lanjut atau mengoperasikan Android pada perangkat yang secara resmi dirilis dengan menggunakan sistem operasi lain (Kaswandari, 2017).

Android dianggap sebagai platform masa depan yang lengkap, terbuka dan bebas sebagai berikut (Safaat, 2012): 
1. Lengkap (complete platform), para desainer dapat melakukan pendekatan yang komprehensif ketika mereka sedang mengembangkan platform Android. Android merupakan sistem operasi yang aman dan banyak menyediakan tools dalam membangun software dan memungkinkan untuk peluang pengembangan aplikasi.

2. Terbuka (open source), platform Android disediakan melalui lisensi open source, pengembang dapat dengan bebas untuk mengembangkan aplikasi. Android sendiri menggunakan Linux karnel 2.6.

3. Bebas (Free Platform), Android adalah platform atau aplikasi yang bebas develop. Tidak ada lisensi atau biaya royalti untuk dikembangkan pada platform Android. Tidak ada biaya keanggotaan diperlukan. Tidak diperlukan biaya pengujian. Tidak ada kontrak yang diperlukan. Aplikasi untuk Android dapat didistribusikan dan diperdagangkan dalam bentuk apapun.

\section{METODE PENELITIAN}

Penelitian ini adalah penelitian eksploratif dan deskriptif analisis untuk inventori tempat makan, toko oleh-oleh, dan destinasi wisata yang memiliki komponen sebagai atraksi wisata gastronomi di Kota Ternate. Pada tahap ini, metode yang dilakukan adalah melakukan identifikasi restoran/destinasi unggulan gastronomi sebagai tujuan wisata dengan memuat: nama restoran/destinasi gastronomi, lokasi, aksesibilitas, amenitas, pengelola, deskripsi umum, nilai unik dan unggul. Selain itu diperlukan juga:

1) Data koordinat GPS tiap lokasi restoran atau destinasi gastronomi sebagai komponen atraksi wisata, yang diperoleh melalui pengukuran.

2) Data atribut, diperoleh dari Dinas Kebudayaan dan Pariwisata Kota Ternate, PHRI, asosiasi kafe dan restoran, dan sektor publik dan privat juga masyarakat. Disertai survei lapangan.

Pengolahan data yang dilakukan adalah:

1) Perancangan program: Akan ditentukan hasil akhir dari aplikasi yang telah dibuat, yaitu meliputi perancangan sistem, user interface, dan activity yang akan dijalankan oleh user.

2) Perancangan Sistem Aplikasi: Dilakukan perancangan mengenai sistem aktivitas yang ada pada aplikasi dengan menggunakan metode UML (Unified Modelling Language). UML adalah bahasa standar yang digunakan untuk menjelaskan dan menvisualisasikan artifak dari proses analisis dan desain berorientasi objek.

Alur penelitian yang dilakukan adalah data deskripsi dan data lokasi (GPS) bahan baku, deskripsi lokasi menu di restoran, home industry, cooking class dan story telling Ternate yang menyertainya kemudian di-plot ke dalam rancangan aplikasi dengan mengidentifikasi fitur, memposisikan dalam Google maps, dengan menggunakan interface, serta location Based Service. Setelah dilakukan fase terakhir yaitu pengujian aplikasi berupa peta yang disusun secara tematik dengan menampilkan semua inventori data gastronomi Ternate sebagai atraksi wisata yang terindetifikasi dengan dukungan lampiran berupa foto dan deskripsi singkat sebagai hasil akhir penelitian ini.

\section{HASIL DAN PEMBAHASAN}

\section{Pengumpulan Data}

Peneliti melakukan desk study terhadap database dari naskah "Potensi Wisata Kuliner 2017". Penelusuran data dilanjutkan dengan melakukan rekonfirmasi ulang melalui internet dan wawancara dengan sumber lokal di Kota Ternate. Dari penelusuran tersebut diperoleh data sebagai berikut: 
Makanan/Minuman Otentik Kota Ternate

Tabel 1. Makanan/Minuman Otentik Ternate

\begin{tabular}{|c|c|c|c|c|c|c|}
\hline No & $\begin{array}{c}\text { Nama } \\
\text { Makanan/Minuman }\end{array}$ & $\begin{array}{l}\text { Deskripsi } \\
\text { (harga, } \\
\text { food story) }\end{array}$ & $\begin{array}{c}\text { Resep (bahan } \\
\text { baku/cara } \\
\text { pengolahan) }\end{array}$ & $\begin{array}{c}\text { Food } \\
\text { presentation }\end{array}$ & $\begin{array}{l}\text { Kandungan } \\
\text { nutrisi }\end{array}$ & Foto \\
\hline 1 & & & & & & \\
\hline 2 & & & & & & \\
\hline
\end{tabular}

Sumber: Diolah oleh peneliti, 2021

Tempat Makan di Kota Ternate

Tabel 2. Rumah Makan di Kota Ternate

\begin{tabular}{|c|c|c|c|}
\hline $\begin{array}{c}\text { No } \\
\text { Makan }\end{array}$ & $\begin{array}{c}\text { Deskripsi (harga, alamat, } \\
\text { keunikan) }\end{array}$ & Foto & $\begin{array}{c}\text { Maps } \\
\text { (Directions, } \\
\text { Data GPS, } \\
\text { jarak) }\end{array}$ \\
\hline $\mathbf{1}$ & & & Pengunjung \\
\hline $\mathbf{2}$ & & & \\
\hline
\end{tabular}

Sumber: Diolah oleh peneliti, 2021

Toko Oleh-Oleh

Tabel 3. Toko Oleh-Oleh

\begin{tabular}{|c|c|c|c|c|c|}
\hline No & $\begin{array}{c}\text { Nama Toko Oleh- } \\
\text { Oleh }\end{array}$ & $\begin{array}{c}\text { Deskripsi (harga, } \\
\text { pengelola, } \\
\text { keunikan) }\end{array}$ & Alamat & $\begin{array}{c}\text { Maps (Directions, Data } \\
\text { GPS, jarak) }\end{array}$ & Foto \\
\hline 1 & & & & & \\
\hline 2 & & & & & \\
\hline
\end{tabular}

Sumber: Diolah oleh peneliti, 2021

Potensi Lokal di Kota Ternate (Destinasi Budaya, Heritage, Alam, Event, Artisan Bahan Makanan, Cooking Class dll)

Tabel 4. Potensi Lokal di Kota Ternate

\begin{tabular}{|c|c|c|c|c|c|}
\hline No & Nama & $\begin{array}{c}\text { Deskripsi (harga, } \\
\text { pengelola, } \\
\text { keunikan) }\end{array}$ & Alamat & $\begin{array}{c}\text { Maps (Directions, Data } \\
\text { GPS, jarak) }\end{array}$ & Foto \\
\hline 1 & & & & & \\
\hline 2 & & & & & \\
\hline
\end{tabular}

Sumber: Diolah oleh peneliti, 2021

Semua data lalu diolah kembali menjadi fitur yang lalu dilanjutkan dengan tahap perancangan. Tahap perancangan adalah menentukan desain sesuai dengan kebutuhan user yang kemudian akan diimplementasikan pada perangkat smartphone. Tujuannya adalah agar dapat meningkatkan sistem informasi wisata gastronomi di Kota Ternate sehingga wisatawan mudah menjangkau destinasi wisata gastronomi. 


\section{Use Case Diagram Sistem}

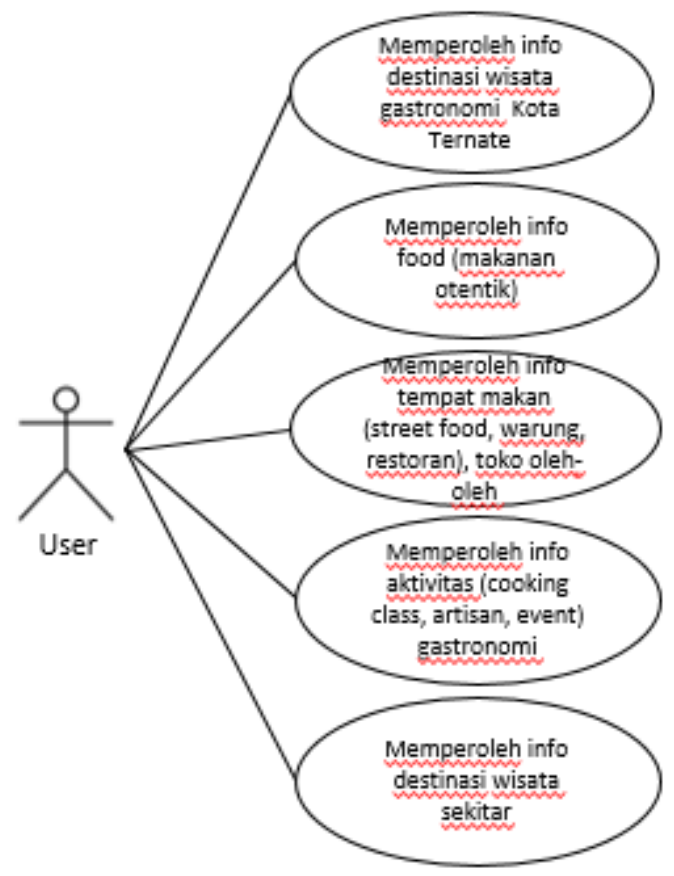

Gambar 1. Use Case Diagram Sistem

\section{Aktivitas Diagram Wisata Gastronomi}

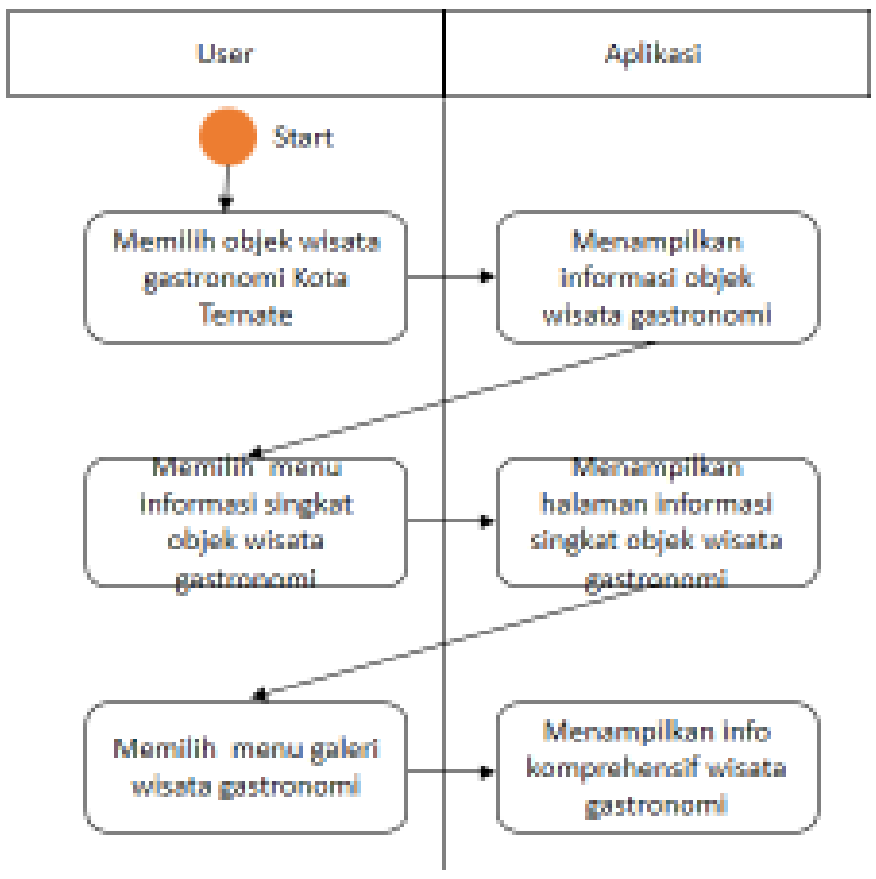

Gambar 2 . Aktivitas Diagram Wisata Gastronomi

\section{Implementasi Sistem}

Yang dimaksud dengan desain sistem adalah suatu gambaran atau perancangan dari sistem yang akan dibangun. Aplikasi dimulai dengan menampilkan halaman pembuka atau splash screen. Halaman aplikasi lalu otomatis berpindah ke menu home berisi image dan pilihan fitur di Kota Ternate. User lalu memilih salah satu thumbnail berupa satu fitur maka akan tampil informasi yang berkaitan dengan fitur tersebut. 


\section{Tampilan Menu Utama}

Halaman utama merupakan tampilan pembuka ketika aplikasi mobile wista gastronomi pertama kali dijalankan. Splash screen ini akan tampil selama 5 detik sebelum masuk ke menu utama aplikasi.

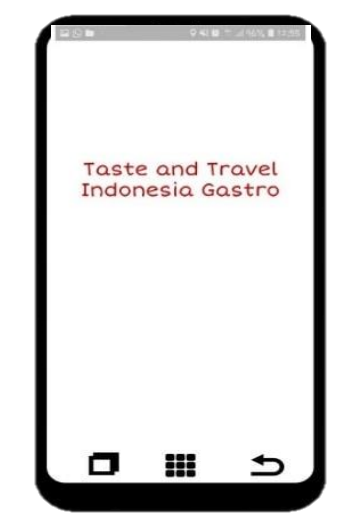

Gambar 3 Tampilan Splash screen aplikasi wisata gastronomi

\section{Tampilan Menu Utama Aplikasi}

Halaman menu home terdiri dari 3 image yang berjalan bergantian (carousel) serta 6 fitur, yaitu 'About Us', 'Food, Restaurant', 'Activity', 'News', dan 'Education \& Research'. Terdapat juga list 'City'. Selain itu, ada thumbnail untuk pilihan bahasa, yaitu Bahasa Indonesia dan Bahasa Inggris. User dapat meng-klik thumbnail yang diinginkan di menu home.

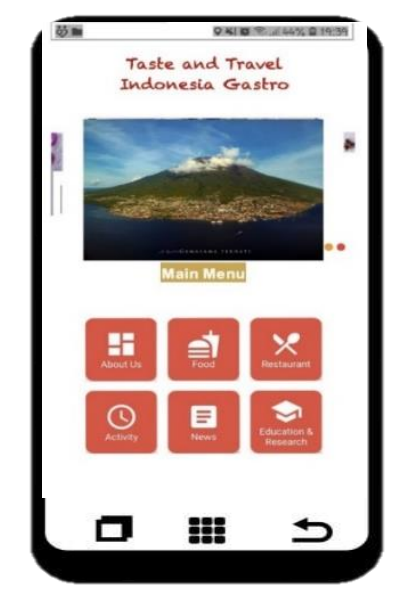

Gambar 4. Tampilan Menu Home aplikasi wisata gastronomi

\section{Tampilan Menu 'About Us'}

'About Us' menampilkan profil aplikasi wisata gastronomi. User dapat mengetahui fitur unggulan, keunikan, dan tujuan pembuatan aplikasi wisata gastronomi yang sedang digunakannya. 


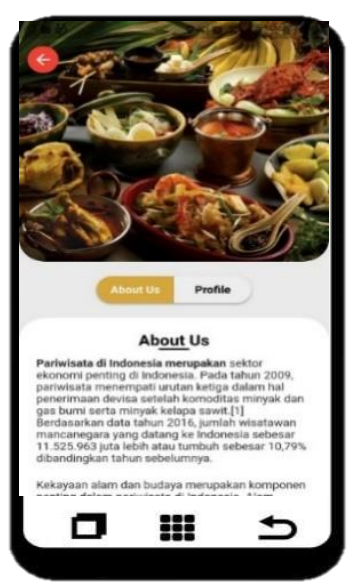

Gambar 5 Tampilan Menu 'About Us' aplikasi wisata gastronomi

\section{Tampilan Menu 'Food'}

Di bawah ini adalah tampilan menu 'Food' di aplikasi wisata gastronomi.

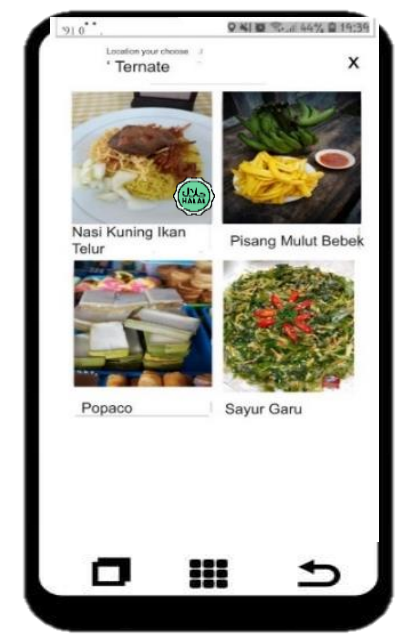

Gambar 6 .Tampilan Menu 'Food' aplikasi wisata gastronomi

\section{Tampilan Menu 'Restaurant'}

Menu 'Restaurant' memuat fitur berupa deskripsi, alamat, serta testimoni dari pengunjung yang datang. Image yang ditampilkan di menu 'Resturant' merupakan thumbnail yang dapat di-klik oleh user. Sebagai penunjang, terdapat fitur jarak yang memudahkan user untuk perkiraan waktu dari lokasi awal penggunaan. 


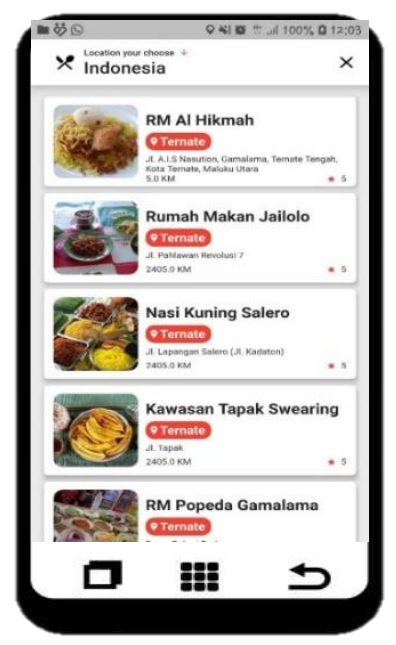

Gambar 7. Tampilan Menu 'Restaurant' aplikasi wisata gastronomi

\section{Tampilan Menu 'Activity'}

Di bawah ini adalah tampilan menu 'Activity' di aplikasi wisata gastronomi

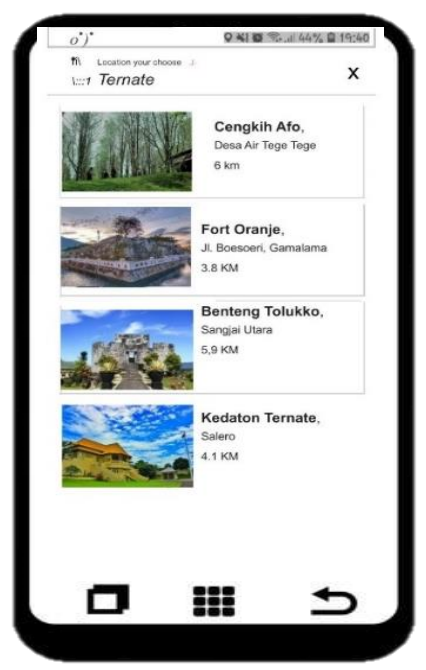

Gambar 8. Tampilan Menu 'Activity' aplikasi wisata gastronomi

\section{Tampilan Menu 'News'}

'News' menampilkan berita-berita seputar kota yang dituju, dalam hal ini adalah Kota Ternate. Di dalam menu 'News' ini akan di-link-kan dengan sumber berita utamanya. 


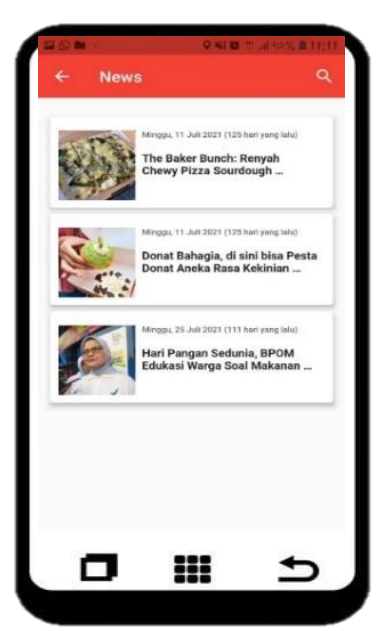

Gambar 9. Tampilan Menu 'News' aplikasi wisata gastronomi

\section{Tampilan Menu 'Education \& Research'}

Menu 'Education \& Research' menampilkan riset dan artikel yang berkaitan dengan dunia kepariwisataan secara umum dan juga tentang Kota Ternate secara lebih spesifik.

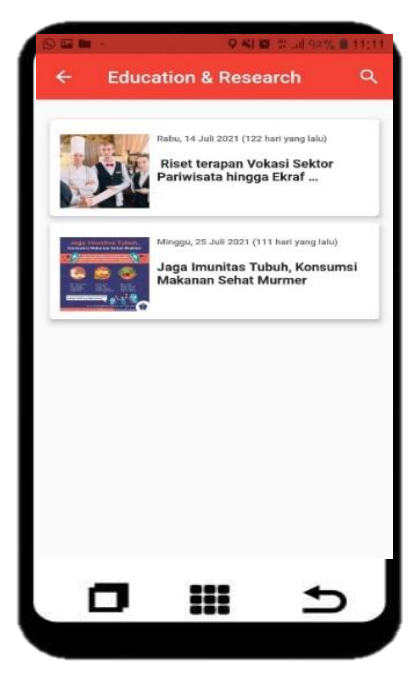

Gambar 10. Tampilan Menu 'Education \& Research' aplikasi wisata gastronomi

\section{Tampilan Menu 'City'}

Menu 'City' akan menampilkan image, profil, dan peta yang akan terhubung dengan Google Maps jika user meng-klik thumbnail-nya. 


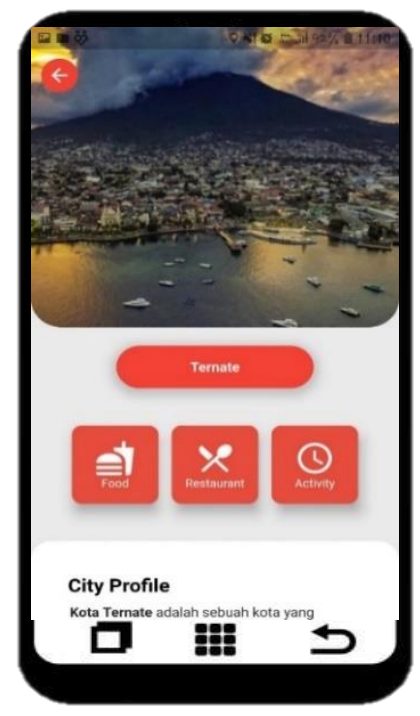

Gambar 11. Tampilan Menu 'City' aplikasi wisata gastronomi

\section{KESIMPULAN}

Hasil dari penelitian ini adalah terbentuknya rancang bangun aplikasi wisata gastronomi di Kota Ternate. Fitur utama yang ditampilkan di dalam aplikasi wisata gastronomi ini adalah makanan otentik, tempat makan/restoran, dan aktivitas. Setiap fitur dibuat komprehensif sehingga user akan mendapatkan informasi yang lengkap saat akan berwisata gastronomi. Selain fitur utama, aplikasi juga dilengkapi dengan data pelengkap seperti 'News' dan 'Education \& Research'. Pemetaan informasi yang akan tersedia untuk memberikan nilai edukasi yang komprehensif bagi pengembangan wisata gastronomi di Kota Ternate.

Tampilan aplikasi wisata gastronomi berbasis Android ini juga dirancang dapat memberikan kemudahan bagi wisatawan dalam mencari rute ke objek wisata yang dituju. Selain itu, dari segi visual, aplikasi yang dibangun memiliki desain yang menarik dengan visualisasi image serta user friendly sehingga mudah dipahami oleh wisatawan.

Dari hasil penelitian yang dilakukan masih banyak kekurangan pada aplikasi wisata gastronomi di Kota Ternate terkait beberapa rumah makan/objek destinasi/aktivitas di Kota Ternate yang lebih baru untuk dapat dimasukkan sebagai list data di kemudian hari. Aplikasi wisata gastronomi berbasis Android ini juga belum diujicobakan secara terbuka dan dikenalkan kepada khalayak sehingga dapat diketahui kekurangannya untuk user yang berkepentingan. Disarankan untuk penelitian yang lanjutan dengan objek yang sama dan kriteria yang sama, serta bisa dikembangkan lagi menjadi aplikasi yang lebih multiguna.

\section{Ucapan Terima Kasih}

Tim Peneliti menyampaikan terima kasih kepada Deputi Bidang Penguatan Riset dan Pengembangan Kementerian Riset dan Teknologi/ Badan Riset dan Inovasi Nasional (Kemristek/BRIN) yang telah memberikan dana hibah penelitian dosen pemula dengan Surat Perjanjian Penugasan Pelaksanaan Program Penelitian Nomor 064/E4.1/AK.04.PT/2021 tanggal 12 Juli 2021. Peneliti juga mengucapkan rasa terima kasih kepada LPPM Institut Ilmu Sosial dan Manajemen STIAMI yang telah memfasilitasi kegiatan PDP dan membimbing penelitian ini mulai dari penyusunan proposal hingga laporan penelitian. 


\section{DAFTAR PUSTAKA}

Anonim. 2016. Pengertian Sistem Informasi: Fungsi Dan Komponen Sistem Informasi.[Online:Tersedia] http;//www.Kumpulan.net/2016/10/pengertian-sisteminformasi Html. Diakses pada 22 Februari 2021.

Anonim. 2013. Android (Sistem Operasi). [Online:Tersedia] https://id.wikipwdia.org/wiki/Android_(sistem_operasi). Diakses pada 22 Februari 2021.

Husein, Muhammad Fakhri dan Amin Wibowo. 2006. Sistem Informasi Manajemen. Edisi Revisi. Yogyakarta: UPP STIM YKPN Yogyakarta. Diakses pada 17 Februari 2021.

Juhadi dan Dewi Liesnoor.2001. Desain Dan Komposisi Peta Tematik. Semarang: BP2SIG. Diakses pada 21 Januari 2021.

Kaswandari, Y. 2017. Rancang Bangun Sistem Kendali Tirai Vertical Blind Dan Lampu Ruangan Melalui Smartphone Android Berbasis Arduino. Tesis. Politeknik Negeri Sriwijaya. Palembang. Diakses pada 22 Oktober 2021.

Permanasari, Intan. 2007. Aplikasi SIG Untuk Penyusunan Basis Data Jaringan Jalan Di Kota Magelang. Tugas Akhir Program Survey dan Pemetaan Wilayah. Semarang: Jurusan Geografi Fakultas Ilmu Sosial Universitas Negeri Semarang. Diakses pada 22 Februari 2021.

Richards, G. 2015. Evolving Gastronomic Experiences: from food to foodies to foodscapes. Journal of Gastronomy and Tourism 1 (5-17). Diakses pada 22 Januari 2021.

Safaat,Nazruddin h. 2012. Pemrograman Aplikasi Mobile Smartphone dan Tablet PC berbasis android. Cetakan Pertama, Edisi Revisi. Bandung: Penerbit Informatika Bandung. Diakses pada 14 Januari 2021.

Soekidjo. 1994. Pengembangan Potensi Wilayah Ternate. Jakarta: PT Gramedia Pustaka Utama.

Turgarini. 2018. Gastronomi Sunda Sebagai Daya Tarik Wisata Kota Bandung. Yogyakarta: Universitas Gadjah Mada. Diakses pada 29 Desember 2020.

Turgarini. D., Pratiwi, II., Priyambodo, TK., 2021. Digitalization activities in gastronomy tourism, Proceeding of the 4th International Seminar on Tourism (ISOT), Bandung. Diakses pada 22 Desember 2020.

WA, Marsum. 2001. Restoran dan Segala Permasalahannya. Yogyakarta: Penerbit Andi.

Wardani. Z., Baiquni, M., 2012. Persepsi Pelaku Bisnis Pariwisata terhadap Regional Branding Solo, The Spirit of Java. Jurnal Bumi Indonesia 1 (1). Yogyakarta: Universitas Gajah Mada. Diakses pada 22 Februari 2021. 